\title{
Spiritual-moral values and methodological aspects of the Turkic thinkers of the epoch of the great Silk Road
}

\author{
A.Y. Baltabayeva - G. Rizakhojayeva
}

DOI: $10.18355 / X L .2019 .12 .03 .08$

\begin{abstract}
The field of education has always acted as a system-forming factor in the life of any state, all over the world, it is an outpost of the future, dominant in the process of national modernization, the main condition for an economic and social breakthrough in the coming century.

The education system of the Republic of Kazakhstan is focused on entering the world educational space. Therefore the quality of education is considered in the context of compliance of the level of educational services received with international standards and norms. Today, the priority is to achieve the quality of training that will enable them to compete in the international labor market. In the conditions of market relations and increasingly complex requirements for the content of education, ways of organizing the educational process, it is necessary to search for new reserves for improving the quality and effectiveness of professional training of future specialists in the field of tourism based on national values.

The aspiration of the Republic of Kazakhstan to equal and competitive existence in the international, economic and educational space, caused by the processes of globalization, has led to a change in the social order of society. Modern education is an essential element of our society and culture, capable of preserving the sociocultural specificity of a country, promoting youth development and its integration into traditional culture, and helping young people to choose a way of life that is adequate to the values of our people. The article deals with one of the urgent problems of professional training of future specialists in the field of tourism based on national values, whose origins go back to the legacy of Turkic scholars. The article also provides some methods, methods, and forms of using the heritage of Turkic scholars of the Great Silk Road epoch in the process of professional training of tourism specialists in higher educational institutions of the Republic of Kazakhstan.
\end{abstract}

Key words: Silk Road, Turkic thinkers, translation, moral values, tourism

\section{Introduction}

The intervention of the Republic of Kazakhstan in the world of education was subject to the displacing of cardinal revisions in the system of higher education. In connection with this, in the university system, there is a search for the way to a new scenario. It concerns the achievement of the principally new goals of higher education, which is in the development of a new personality level of individuality and unity and the world and is committed to the development of a separate personality and community.

Before the system of higher professional education of the Republic of Kazakhstan, new tasks are identified for implementing the concept of developing education, which require comprehensive consideration of the complex and contradictory socio-economic and political processes taking place in our society and the state, as well as patterns and trends in the development of global, European and domestic higher education systems, vocational education.

Kazakhstani universities implement multi-level vocational educational programs in various specialties of higher vocational education. In order to implement

XLinguae, Volume 12, Issue 3, June 2019, ISSN 1337-8384, eISSN 2453-711X 
these programs in the context of social protection of students and increase the mobility of graduates, it is necessary to follow general and innovative principles and methods in the learning process.

The most important role of education at the present stage is the transformation of the process of preparing future specialists into the fundamental sphere of human activity. In this case, to work in a competitive professional environment, specialists must master new technologies, quickly adapt to changing conditions of life, be professionally, personally, and socially competent. Therefore, in the modern conditions of modernization and informatization of education, the problem of training professionally competent specialists becomes particularly relevant.

Taking into account the above circumstances, we conducted a scientific study to determine the level of use of the heritage of great scientists in the process of training future professionals in the field of tourism in higher education institutions.

\section{The relevance of research:}

Today, the tourism industry in Kazakhstan needs intensive development. The resources of our country allow us to organize this sector of the economy in such a way as to obtain greater profits. At the end of the XX century. Human history has reached a new phase in the formation of an information civilization. The tourism industry simultaneously plays a transformative and managerial role. According to consultants, the tourism industry is one of the most profitable sectors of the economy of the region in question. This industry has many different sectors of the economy. The main tourist routes at present, suggesting a more detailed study of the local historical, architectural and archaeological heritage. This fact provides you with a comfortable living environment for both tourists and researchers (Toybazarova N.A.:104]. For the development of the tourism industry requires training of highly qualified, competent specialists in this field. To manage professional development, future specialist requires personal moral qualities. Personal qualities of a tourism specialist or personal competencies as part of his general professional training show personal preparedness for professional activities.

The analysis of the history of pedagogy shows that in the formation of the system of distinctive personality education in Turkic society, a special place is occupied by the ancient Turkic culture (V. Sh. Khetagurova:104). Due to this circumstance, taking into account the renewal of consciousness in the spiritual sphere, the tendency to reassess human values, we believe that the use of the vast and rich heritage of our ancestors in educating future generations is a requirement of today. Therefore, a comprehensive, systematic study of the essence of ideas about the education of the individual among the ancient Turkic people, the characteristics of their use in modern practice, as well as the study of the continuity of scientific ideas of the past and present are one of the urgent problems in the preparation of future specialists.

Intangible cultural heritage is a combination of traditional forms of cultural activities for this community, which form a sense of identity and continuity among its members (Basçi e S.: 75). The scientific literature presents various options for the classification of objects of cultural heritage (Ibrayeva K. J.: 513). Objects of cultural heritage include oral folk art, performing arts, festive ceremonial culture, gaming culture, and technology. Cultural identity is inextricably linked with the protection of intangible cultural heritage, transferring it to future generations, which is possible due to its involvement in the tourism system.

In scientific studies, the use of intangible cultural heritage in the field of tourism is considered from the point of view of sustainable development of tourism, while emphasizing that intangible cultural heritage is a tourist asset (Naribayev M., p.188). Depending on the degree of development and features of the organization of tourist activities in a particular country, the degree of involvement of intangible 
cultural heritage in the tourism sector may be different. It should be emphasized that the deeper the intangible cultural heritage is integrated into the sphere of tourism, the more it is protected from loss and oblivion. From this point of view, it is important to understand how types of tourism are developed in a particular country, based on the use of intangible cultural heritage, and what is its role in the implementation of tourism activities. Intangible cultural heritage is the basis for such types of tourism as ethnic, religious, cultural, gastronomic, and others. The inclusion of intangible cultural heritage in the tourist turnover contributes to the formation of tolerance of the population and tourists (Tomski G.: 62-66).

In our study, we focused on the ideas about educating a specialist's personality contained in the legacy of the great Turkic scientists, from a theoretical perspective, we considered the model of a professional personality of a specialist presented in their works, revealed some effective combinations of world trends with elements of national existence in the future professionals 'professional development. Kazakhstan is almost unknown in the world as a tourist destination, although lands have long provided links between China and Europe (Karabatyrova A. et al., num. art 85). We tried to reveal the level of knowledge by students of national ideas in the content of academic disciplines, as well as their use in practice, tried to form them through the organization of various forms of education.

Objectives of the research: to identify and describe the possibilities of applying the heritage of the Turkic thinkers, its methodological aspects and place in the formation of the professional personality of future specialists in the field of tourism at the Kh.A.Yassawi International Kazakh - Turkish University consider methodological and theoretical conditions, determine the essence, content and features of the use of the heritage of the great Turkic thinkers in the professional training of future specialists; reveal the features of the use of the heritage of Turkic thinkers in the formation of the professional competence of the individual; theoretically substantiate and experimentally test the effectiveness of applying the foundations of the heritage of the Turkic thinkers in shaping the professional identity of future specialists in the field of tourism at the university.

\section{Research methods:}

The main methods of our research on the formation of professional personality of future specialists in the field of tourism based on the use of the heritage of Turkic thinkers in the process of professional training at the university were theoretical analysis and synthesis, comparison and synthesis, modeling, studying the experience of applying the heritage of the great Turkic thinkers in the process of learning, observation. In scientific work, the following research methods were used to solve the tasks and check the initial assumptions: general logical methods and techniques (analysis of philosophical, methodological, psychological, pedagogical, regulatory and other literature on the problems of training specialists taking into account national values, synthesis, abstraction, generalization, analogy, structural-functional method and probabilistic-statistical methods); methods of theoretical knowledge (axiomatic, formalization, deduction, ascent from the abstract to the concrete); empirical research methods: (observation, interviewing, questioning, bibliographic method; experiment in vivo, comparison, description, monitoring, measurement); a systematic approach in conducting historical, pedagogical and logical analysis, synthesis and analysis of pedagogical experience; modeling of pedagogical processes; pedagogical design used for the development of regulatory and software and technology support. The training methodology was developed taking into account national values, as well as experimental work was carried out to test the effectiveness of the use of the heritage of Turkic thinkers in shaping the professional personality of future specialists in the field of tourism; refined indicators and criteria for evaluating the effectiveness of the

XLinguae, Volume 12, Issue 3, June 2019, ISSN 1337-8384, eISSN 2453-711X 
conditions identified; a pedagogical experiment was conducted; an educational and methodological support was developed for the educational process of applying the heritage of Turkic thinkers, aimed at shaping the professional identity of the future specialist in the field of tourism.

\section{The results of the study:}

For the experimental work, we chose students in the specialty 5B090200 "Tourism" of the Kh.A.Yassawi International Kazakh - Turkish University and South Kazakhstan State University.

With students from the experimental group, classes on the subject "Introduction to the specialty" were held to cover all the topics of the course, supplemented in accordance with the goal of our research with ideas on the formation of the professional personality of a specialist.

And for students of the control group classes were held without deviation from the curriculum. In this case, the assimilation of information regarding the formation of a professional personality of a specialist was carried out through the independent work of students and independent work of students under the guidance of a teacher.

When discussing this topic with students, such methods as design, cases, training, group works, role-playing games, elements of research work in resolving situations, etc. were effectively used. The student-oriented technological methods of teaching allow students to discover their cognitive abilities, develop their intellect, emotions, professional bias and aspirations, value orientations for professional activities. Given this circumstance, higher educational institutions create the necessary conditions for an individual approach to the creative nature of the personality, for the manifestation of refined skills in activities.

First of all, students are given the right to choose educational programs and individual learning paths. At the same time, a practical lesson on the topic "The culture of communication of a specialist in the heritage of great scientists" aroused particular interest among the students of the experimental group. During the meeting, the discussion revolved around the question "What should be the relationship between teacher and student?" During the discussion of this issue, it was revealed that students hold two different positions.

Most of the students were in favor of the teacher adhering to strict methods in the classroom, while another part acknowledges the effectiveness of gentleness in communication between teachers and students since the 21 st century is guided by the setting to mitigate strict requirements. When we asked students to explain the reasons for two different points of view, most of them said that today students are not psychologically prepared at the proper level, the severity instills fear in them, and they cannot freely convey their thoughts. For this reason, they are more in need of friendships.

Another part of the students argues that they should be accustomed to strict discipline from the very first days, following the statement of B. Momyshuly "Being in order will not be a slave" (Mirzamohmmadi M. H. et al.).

In this case, the teacher, asking how you feel about the words of al-Farabi, led the views of the Turkic scholar on the relationship between teacher and student, on the moral aspect of this relationship. If a teacher wants to see in his students such qualities as honesty, politeness, virtue, justice, then they must be in him. Al-Farabi, in his work "The book about what you need to know to study philosophy," wrote that a person engaged in teaching should be neither too touchy nor too weak. If he is too strict, then the disciples will dislike him. If he is too soft, then from the side of the students, there will be a danger of underestimating the teacher, looking at his science with laziness.

After that, there were certain changes in the views of students. Continuing the discussion, they came to common opinion, replacing rigor with the order, and softness 
with a democratic style. At this point, the second question was asked: "Which of the great scientific methods proposed in the heritage proves its effectiveness at present?" This question caused a slight hitch among students, as they could not say that there are strict, soft, and medium methods. Therefore, the students were assisted in the form of leading questions. To the question: "How to understand the middle method cited in the works of great scientists?" The students gave the following answer: "The middle method should reveal the closed students, and hurry students to call for patience." The teacher asked the third question: "What traditional methods lead to obtaining these results?" The students started thinking again. Again, they were assisted, namely: for open, active students, a large amount of exercise was given based on the use of the "question-answer", "brain assault, "and closed students with the aim of strengthening their belief in themselves were stimulated by short-term tasks, which require methods that give quick results. All this showed that the students did not read the works of AlFarabi, which dealt with didactic problems of the relationship between the Teacher and the students. Therefore, the topics of this elective course are particularly interested students. Before concluding a seminar lesson, we found it expedient to conduct training.

In order to sharpen the relationship between students, the game was "Respectful Word." The task of the exercise is to increase the level of empathy of the participants to each other, the development of the ability to find a common language, more complete recognition of each other. Training participants are placed in the shape of a circle. One of the participants utters a positive, respectful word. And the other participants must find out whom it is dedicated to. Positive, respectful words spoken to each other are as follows: responsible, tenacious, understanding, modest, fair, truthful, etc. The player who has received a respectful word continues the game further. The game does not end until all participants without exception get emotions. This exercise proved how interested participants were doing the tasks. In the final part of the training, the students, responding to the question: "What did the training give you?" Expressed their opinions. So, for example, there was an answer that we are not always talking about the good qualities of each other, and during the training, we learned that our good qualities are appreciated by others. Upon completion of the training, we realized that as a result of joint activities, not only increased the ability to communicate with each other, but it had a direct impact on the development of the personality.

After the training, together with the students, characterizing from a professional position, the praise they received and respectful words, compared them with the views of the great Turkic scholars. Along with this, it was revealed what qualities need to be formed in connection with the demand for professional workers specialists in the field of tourism. Thus, a plan was drawn up for the formation of the professional personality of the future specialist in the field of tourism.

After the lecture sessions for a complete collection of information, we gave the task to the students of experimental groups to systematize the views of the great Turkic scientists on the formation of the professional personality of the specialist. Students of the control groups, having mastered the knowledge within the framework of the curriculum, limited themselves to performing tasks on the topics indicated in the syllabus.

Students of experimental groups discussed the collected information together at seminars and during independent work under the guidance of a teacher, which made it possible to make a system analysis on the model of the professional personality of a specialist in class.

The advantage of the group work method is the possibility to hold a mutual exchange of views between students, come to a common conclusion regarding the formation of a professional specialist's personality, perform tasks, having previously

XLinguae, Volume 12, Issue 3, June 2019, ISSN 1337-8384, eISSN 2453-711X 
divided them among themselves, take steps towards achieving a common goal. This gives impetus to the professional development of students. The mastered, mastered, and turned into skills actions on each topic are evaluated according to the results of lectures, practical exercises, the performance of SIW.

In the process of using case-technology, students are provided with a term paper - a case, that is, a set of teaching and learning materials, which makes it possible to independently master the material. Here the main duty of the teacher is to create conditions for students to independently acquire knowledge. For this purpose, it is necessary to conduct thematic consultations on a mandatory basis, to exercise selfcontrol, and work with multimedia installations. In the course case, lecture materials are given for contact and virtual classes. In the process of conducting a contact lecture, the traditional methodology of studying the discipline was used.

Virtual lectures were held in the form of consultations. Lectures and consultations do not repeat the content of the course case, but the teacher refers to him during lectures and consultations. The student must first know the topic of the lectureconsultation and be prepared according to the case materials for the virtual lecture.

When conducting a specialty "Tourism" with students during a practical lesson of group work on the topic "Model of a professional personality in the heritage of the great Turkic scholars," we found that learning their heritage was the most advantageous.

The purpose of the lesson was to identify in the views of the Turkic scientists a model of a professional personality based on the research by students of their heritage.

Dividing the student group into four small groups, we gave them the following names: 1) the Al-Farabi group, 2) the J. Balasaguni , 3) M.Kashgari group and 4) Kh. A. Yassawi group.

They were given some time for reflection, advice, discussion of materials. After the students expressed their thoughts, views, came to a common decision, the leader of the group or a member of the group should protect the model professional personality of the specialist contained in the legacy of a Turkic scientist in accordance with the names of the groups. Students from all four groups expressed their opinions. Summing up, comparing the views of Turkic scholars regarding the professional identity of a specialist, the students grouped the general qualities of the models as follows: 


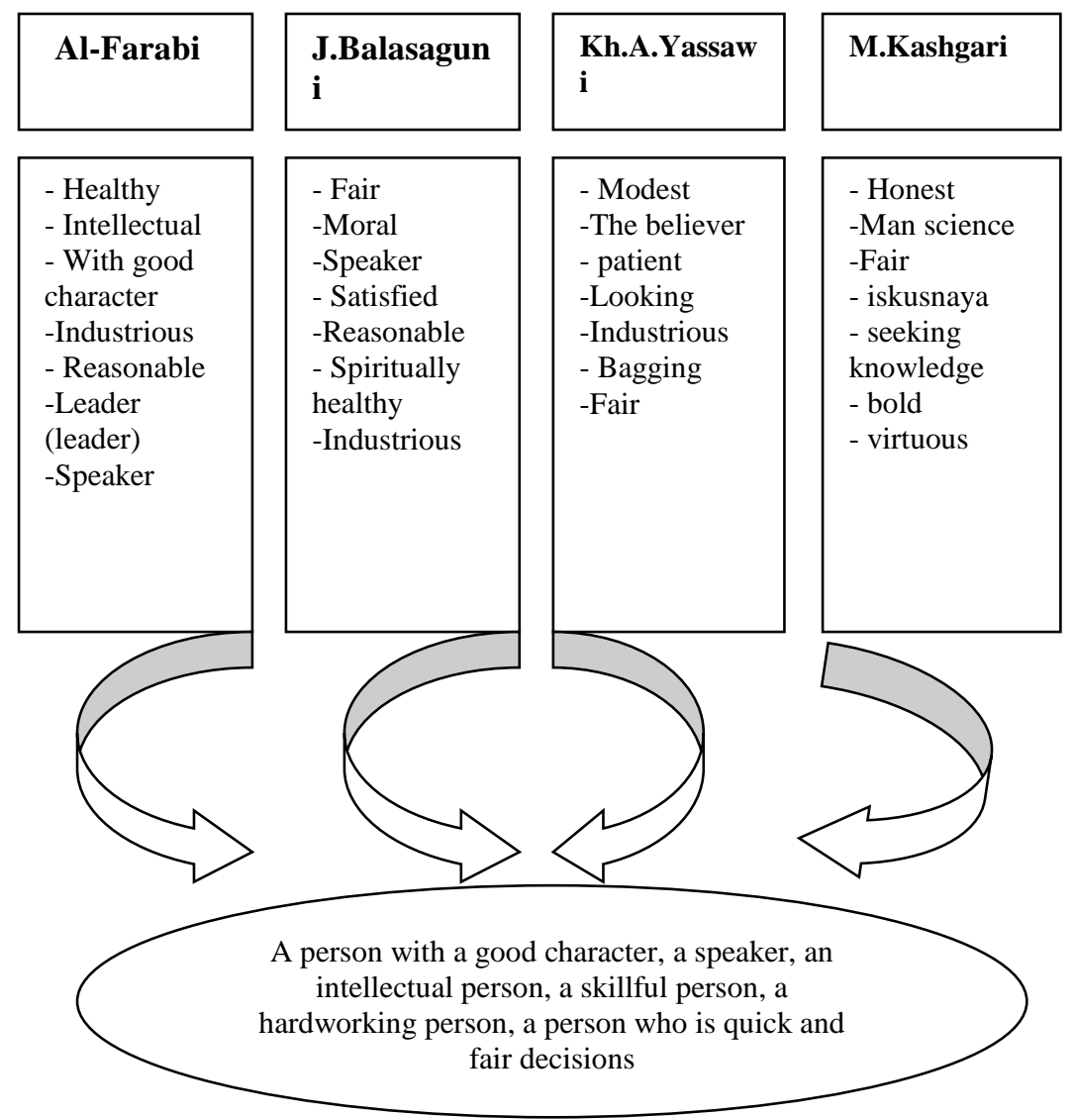

Figure 1- Qualities inherent to the professional identity of a specialist in the legacy of Turkic scholars

The students of each group, based on their analysis of the heritage of the Turkic scholars, identifying the ideas inherent in the professional personality of a specialist, also considered measures for their use in the educational process in higher education institutions.

The evaluation criteria took into account the extent to which the requirements imposed on the professional identity of the student are met according to the views of the great Turkic scholars. After conducting a series of lectures and practical classes, we found that, compared with the data from the previous survey, there were some changes in the professional development of future specialists, that is, we noticed a movement forward. Results are shown in the following table:

Table 1 - Results of experimental and experimental work on the formation of the professional personality of a future specialist at the stage of a formative experiment:

\begin{tabular}{|l|l|l|}
\hline $\begin{array}{l}\text { Indicators of the professio } \\
\text { development of students }\end{array}$ & Experimental group & Control group \\
\hline
\end{tabular}

XLinguae, Volume 12, Issue 3, June 2019, ISSN 1337-8384, eISSN 2453-711X 


\begin{tabular}{|c|c|c|c|c|c|c|c|c|}
\hline & Number & $\begin{array}{l}\text { High } \\
\text { level }\end{array}$ & $\begin{array}{l}\text { Average } \\
\text { level }\end{array}$ & $\begin{array}{l}\text { Low } \\
\text { level }\end{array}$ & Number & $\begin{array}{l}\text { High } \\
\text { level }\end{array}$ & $\begin{array}{l}\text { Averag } \\
\text { level }\end{array}$ & $\begin{array}{l}\text { Low } \\
\text { level }\end{array}$ \\
\hline $\begin{array}{l}\text { Having a comprehensive } \\
\text { knowledge of the necessar } \\
\text { for professional activities } \\
\text { personal qualities } \\
\text { specialist }\end{array}$ & 116 & - & $\begin{array}{l}61 \\
(53 \%)\end{array}$ & $\begin{array}{l}55 \\
(47 \%)\end{array}$ & 108 & - & $\begin{array}{l}60 \\
(55 \%)\end{array}$ & $\begin{array}{l}48 \\
(45 \%)\end{array}$ \\
\hline $\begin{array}{l}\text { Compliance of the } \\
\text { professional activity of a } \\
\text { specialist with the } \\
\text { qualities contained in the } \\
\text { legacy of great scientists }\end{array}$ & 116 & $\begin{array}{l}5 \\
(4 \%)\end{array}$ & $\begin{array}{l}53 \\
(46 \%)\end{array}$ & $\begin{array}{l}58 \\
(50 \%)\end{array}$ & 108 & - & $\begin{array}{l}52 \\
(48 \%)\end{array}$ & $\begin{array}{l}56 \\
(52 \%)\end{array}$ \\
\hline $\begin{array}{l}\text { Specialist aspiration } \\
\text { to the mastery of personal } \\
\text { qualities for professional } \\
\text { activities }\end{array}$ & 116 & $\begin{array}{l}7 \\
(6 \%)\end{array}$ & $\begin{array}{l}42 \\
(36 \%)\end{array}$ & $\begin{array}{l}67 \\
(58 \%)\end{array}$ & 108 & \begin{tabular}{l|}
5 \\
$(5 \%)$
\end{tabular} & $\begin{array}{l}40 \\
(37 \%)\end{array}$ & $\begin{array}{l}63 \\
(58 \%)\end{array}$ \\
\hline Total & 116 & & & & 108 & & & \\
\hline
\end{tabular}

This information shows that, in a certain sense, the scientific information used for personal development in professional activity leads to professional growth, and the latter - to personal development.

\section{The discussion of the results:}

Compared with the data from the initial survey after the work carried out on the basis of the program of the elective course "Ideas on the formation of the professional personality of a specialist in the legacy of Turkic scientists" at the final stage, the results showed positive changes, namely: to the first question from students views contained in the legacy of Turkic scholars regarding the formation of the professional personality of a specialist? Whose views can you tell based on their analysis? ", 26\% of respondents gave the following answer:" I know the ideas of Turkic scientists about the formation of the personality of a specialist and I can justify them by linking with the requirements of today." Along with this, it turned out that many students support the study in higher educational institutions of the heritage of the Turkic scholars and that, through reading their works, it became easier to assimilate the content of historical and pedagogical disciplines. Often there were answers from students who were dominated by the idea that the works of Turkic scholars arouse professional interest among future specialists.

As is evident from the above tables, the elective course "Ideas on the formation of the professional personality of a specialist in the legacy of Turkic scholars" proposed by us had a positive influence on the professional development of specialists. The inclusion in the content of the educational process in higher education institutions of the ideas of the great Turkic scholars regarding the formation of the personality of a specialist arouses interest and develops the cognitive abilities of students.

At the beginning of the study, we conducted a re-survey using the same questionnaires as the first time, in order to clarify the role and place of the heritage of the Turkic scholars in shaping the professional identity of future professionals in the field of tourism. We set a goal to check the effectiveness of the activities carried out under the program of the elective course we proposed. After students answered the re- 
posed questions, we noticed that they had changed somewhat. To the question "How important is the essence of the ideas of the Turkic scholars about the formation of the personality of a specialist to you? What do these ideas give?" $36.2 \%$ of respondents (42 students) answered the following: growing demand for them. These ideas form a specialist as a completely competitive personality. Their leadership in the system of training specialists will contribute to the formation of their national identity. " $44.8 \%$ (52 students) answered that today there is a high demand for the ideas of Turkic scientists about the formation of the personality of a specialist, their use is effective. Moreover, the remaining 19\% (22 students) gave vague answers, thus demonstrating the abstract nature of their thoughts.

When asked about the study of the heritage of Turkic scholars in higher education institutions, $62 \%$ (72 students) indicated the effectiveness of studying the heritage of Turkic scholars in higher education institutions, because the educational process organized in them promotes the assimilation of knowledge, influences the development of character and office ethics in the national style. Along with this, the majority of students studying in the specialty "Tourism" support the advantage and efficiency of studying the works of the Turkic scholars as separate disciplines.

The works carried out on these topics showed that students had increased interest and opportunities to study the heritage of the Turkic scholars. Compared with the data from the previous survey, the number of readers has increased. For example, $26.7 \%$ (31 students) mastered the pedagogical ideas contained in the works of Turkic scholars through monographic research, 31.9\% (37 students) through the media, $41.4 \%$ (48 students) through classes on special courses and specially organized seminars and conversations, by means of independent searches, and also as a result of discussions and exchange of opinions during occupations. From the above information, it can be seen that the understanding of the heritage of the Turkic scientists by the future specialists has slightly increased.

To the question "What factor prevents the enrichment of your professional personal qualities and professional knowledge?" 50\% (58 students) said that there are no obstacles, that if there is an interest and incentive, all the information can be found and that they find it. $26.7 \%$ of respondents (31 students) stated that it is impossible to find in the libraries the works of all Turkic scholars who wish to receive information from originals. $23.3 \%$ (27 students) of respondents gave vague answers. At the same time, the number of students increased, who said that the use of the heritage of Turkic scholars in the educational process has a great educational force. For example, $63 \%$ of students believe that the legacy of Turkic scholars plays a positive role in shaping such personality traits as love for motherland, citizenship, patriotism, and morality. $37 \%$ of students expressed the opinion that, based on the ideas of Turkic scholars, there are high possibilities for the formation of positive moral and virtuous qualities. $61.2 \%$ of respondents (71 students) stated that when studying pedagogical disciplines, there is a continuity between the theories of the formation of professional personal qualities of future specialists and the views of Turkic scholars on the existence and morality of a specialist, that the system of training specialists in higher educational institutions is effectively addressed in connection with views of Turkic scientists. Therefore, maintaining the effectiveness of training based on the integration of sciences, $28.4 \%$ (33 students) because the content of the works of Turkic scientists is philosophical, they associate it with the content of the discipline "Philosophy." 10.4\% (12 students) believe that the knowledge given based on the content of humanitarian and partly natural disciplines can be comprehensively and comprehensively learned and will have a positive impact on the intellectual abilities of a specialist's personality.

To the question "What do you think should be the role and place of public organizations in this direction?" $26.7 \%$ (31 students) answered that they were satisfied with the activity of teachers of pedagogical disciplines towards the formation of

XLinguae, Volume 12, Issue 3, June 2019, ISSN 1337-8384, eISSN 2453-711X 
students' professional and personal qualities, 47.4\% (55 students ) half satisfied, and $25.9 \%$ (30 students) are not at all satisfied. Such a one-sided assessment by the main group of students of teachers' pedagogical disciplines is explained by the following reasons: first, insufficient use of the works of Turkic scientists in shaping the personality of a specialist, secondly, the lack of continuity of pedagogical education with features of national education, that is, a low level of experience combining the views of Turkic scientists with modern ideas of training. When asked about the role of the media in promoting the heritage of Turkic scholars among the population, students note their positive influence on the upbringing of the younger generation. If $82.7 \%$ (96 students) see a positive role in training specialists in programs that correspond to the national mentality, then $17,3 \%$ (20 students) consider the impact of print media and periodicals on the professional identity of a specialist and work culture to be insignificant. They associate them with the human qualities of a specialist. The role of the media in promoting the legacy of Turkic scientists was rated as "good" by $21.5 \%$ (25 students), "satisfactory" - 43\% (50 students), and "unsatisfactory" - 35.5\% (41 students).

Most students said that the activities of public organizations in this direction are limited only to cultural and leisure activities, that in the context of globalization, when there is a devaluation of spiritual and moral values, events are not organized that glorify spiritual values before material values, which, compared to national values, are strongly influenced traditions of the West. 54.3\% (63 students) participating in the experiment consider it necessary to supplement the content of educational programs with national ideas and materials that can become the basis for the formation of a specialist's personality in order to better assimilate the heritage of Turkic scientists. Moreover, 45.7\% (53 students) of the respondents indicate that, along with the additions to the content of the disciplines, the heritage of the Turkic thinkers, when organizing the educational process, it is necessary to adopt national ideas and values.

When comparing a previous organizational experiment with a formative experiment, the identified differences are shown using the following diagrams:

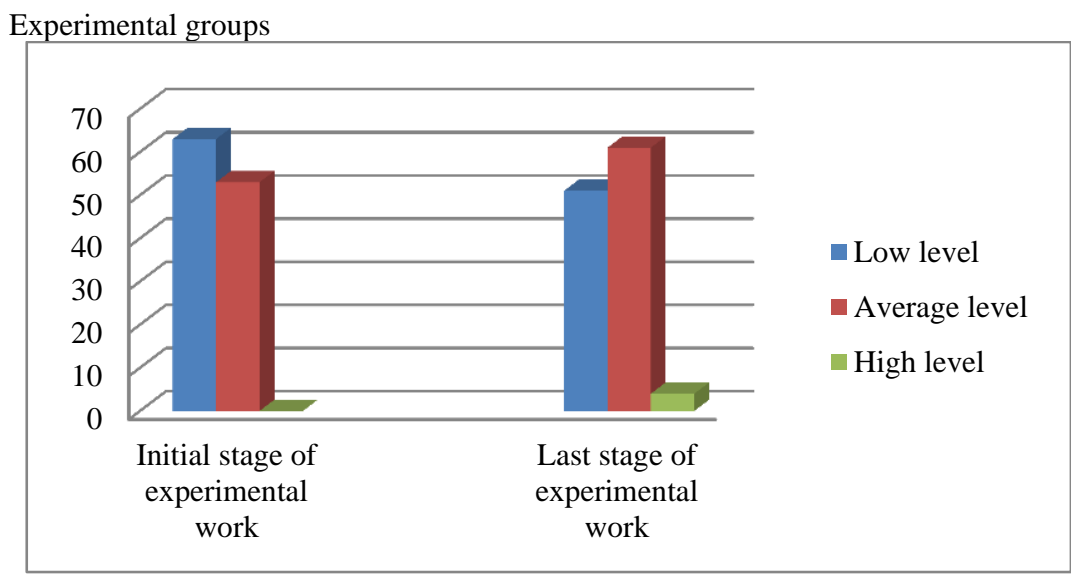

Figure 2 - Diagram revealing knowledge indicators in the formation of the future professional's professional personality in the field of tourism

The above diagram shows the need for a comprehensive knowledge of the personal qualities of the future specialist by the indicators of the professional development of students of experimental groups. 
Experimental groups

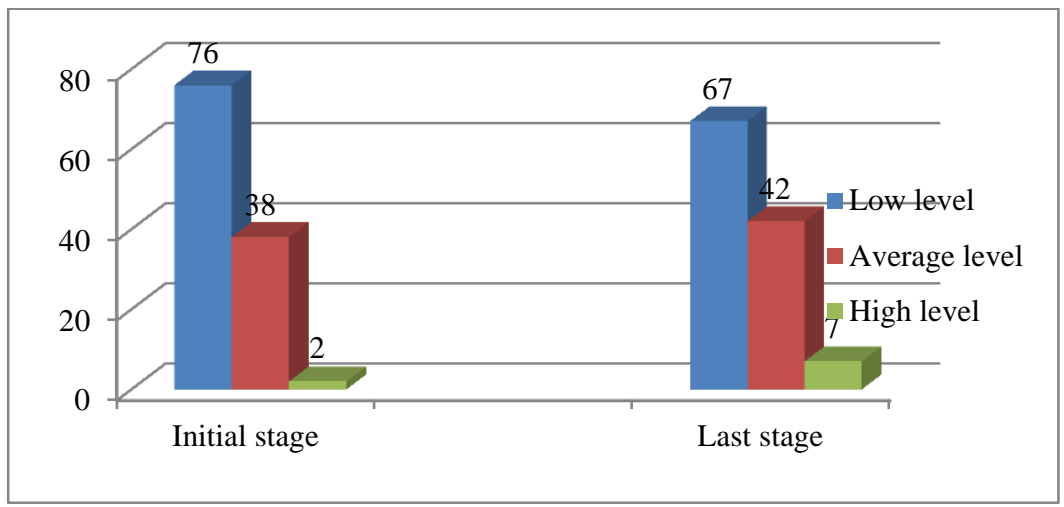

Figure 3 - Striving for the formation of professional and personal qualities in the activities of the future specialist in the field of tuism.

Control groups

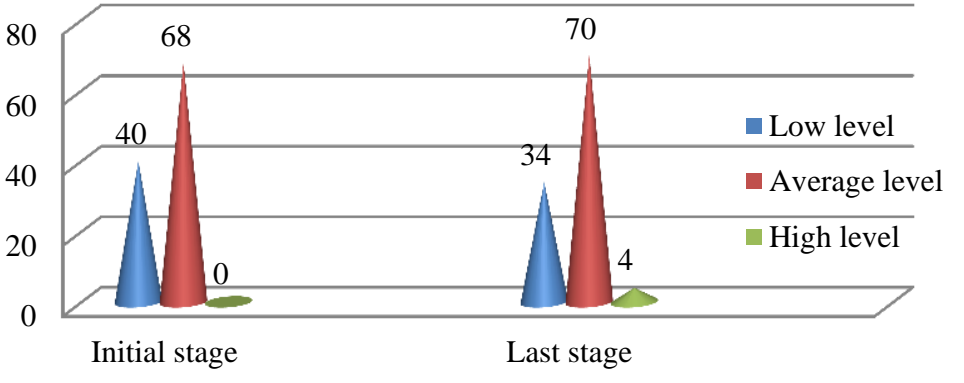

Figure 4 - The diagram revealing knowledge indicators in the formation of the future professional's professional personality in the field of tourism

Control groups

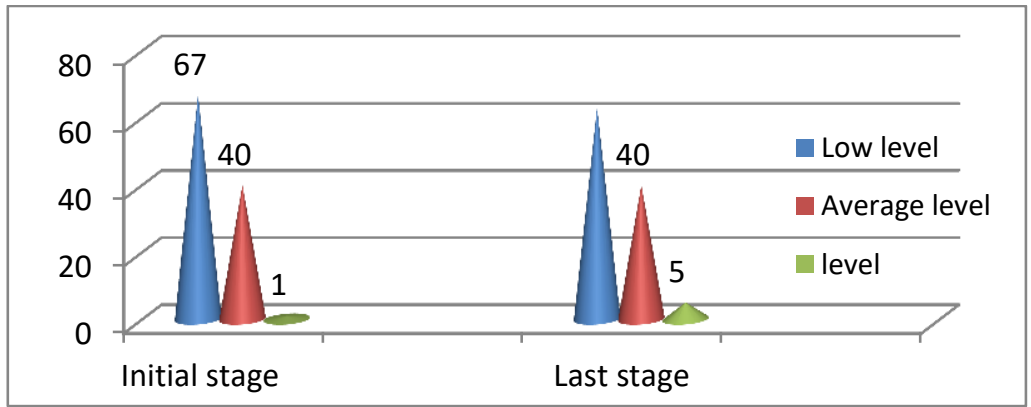

Figure 5 - The pursuit of the formation of professional and personal qualities in the activities of the future specialist in the field of tourism 
The above data on experimental and control groups in the form of specific quantitative differences show the effectiveness of systematic use of the heritage of Turkic scientists in the professional development of a future specialist in tourism, and also testify in favor of confirming the scientific hypothesis put forward at the beginning of this scientific research.

\section{Conclusion}

The results of experimental work show that: the heritage of Turkic thinkers helps the formation of future professional specialists in the field of tourism; increase motivation to learn based on national values; allows the future specialist to identify areas in which more intensive training is required for the formation of professional skills; forms a creative and critical style of thinking, contributes to the formation of professional competence.

Therefore, the expediency and necessity of using the heritage of the Turkic thinkers in the formation of the professional personality of future specialists in the field of tourism is obvious.

Most future specialists are technically and psychologically ready to use the heritage of the Turkic thinkers, and it is necessary to consider and organize new opportunities and priorities for more efficient use of the potential of the heritage of the Turkic thinkers in shaping the professional personality of future specialists. The solution of this task requires an organizational effort on the part of the leaders of education, research and methodological work of scientists and teachers on the introduction of strategies, forms and methods of using the heritage of Turkic thinkers in the educational process of higher educational institutions.

We believe that learning activities in terms of the use of the heritage of Turkic thinkers in shaping the professional identity of future professionals in the field of tourism is complicated by the fact that specialists carry it out in a new professional environment and with new teaching aids. Under these conditions, the nature of the teacher's work changes, he has to implement a number of functions that, in traditional teaching, are sometimes absent. It should be concluded that the teacher's culture becomes a decisive condition for the successful use of the heritage of Turkic thinkers in shaping the professional identity of future professionals in the field of tourism.

We believe that the high degree of development of the competent personality of future specialists in the field of tourism, in terms of using the heritage of the Turkic thinkers, is expressed: in the skills and needs to systematically replenish and expand knowledge of open education technologies through self-education; in the analysis of the real pedagogical process; the ability to study the personality of each individual student; in the ability to study the advantages and disadvantages of their own personality and individual style of professional activity in terms of the use of open education technologies; in the ability to explore the content of educational material, textbooks, teaching aids in terms of choosing the appropriate educational technology.

\section{Bibliographic references}

BASÇI E. S. 2015. 4th International Turkish World Economic Forum, Journal of Economics Bibliography. vol. 2, issue 2, 75 p.

FAKHRY M. AL-FARABI. 2014. Founder of Islamic Neoplatonism: His Life, Works and Influence. Oneworld Publications,

HILL R. 2018. Redefining the Muslim Community: Ethnicity, Religion, and Politics in the Thought of Alfarabi by Alexander Orwin. Comitatus: A Journal of Medieval and Renaissance Studies. vol. 49, issue 1, pp. 260-262.

IBRAYEVA K. J. Address to the historical experience of individual Zh. Balasaguniitls natural phenomenon of modern educational practice. РОССИЯ МОЛОДАЯ, pp. 513-513. 
KARABATYROVA A. et al. 2018. The role of the environment: Silk road in the history of turkic people. Opción, vol. 34, issue 85 ,

MAMMADOVA-KEKECH E. 2016. Age Poetry as Autobiographic Items in the Literature of Turkic Nations.

MIRZAMOHMMADI M. H. et al. 2017. A COMPARISON OF PHILOSOPHICAL BASES AND EDUCATIONAL OPINIONS OF AL-FARABI AND ROUSSEAU //Ad Alta: Journal of Interdisciplinary Research, vol. 7, issue 1,

NARIBAYEV MARAT. 2018. The economic belt of the Silk road: opportunities and risks for Kazakhstan. THE BULLETIN OF THE NATIONAL ACADEMY OF SCIENCES OF THE REPUBLIC OF KAZAKHSTAN, issue 6, 188 p.

ORDABAYEV M. 2017. Tourism in East Kazakhstan region: potential economic importance and development prospects. THE BULLETIN OF THE NATIONAL ACADEMY OF SCIENCES OF THE REPUBLIC OF KAZAKHSTAN, issue 2, 266 p.

TOMSKI G. 2017. EDUCATIONAL MODULE. Bulletin de l'Académie Internationale Concorde, issue 2, pp. 62-76.

TOYBAZAROVA N.A. - NAZAROVA G. 2018. The modernization of education in Kazakhstan: trends, perspective and problems, THE BULLETIN OF THE NATIONAL ACADEMY OF SCIENCES OF THE REPUBLIC OF KAZAKHSTAN. issue $6,104 \mathrm{p}$.

KHETAGUROVA V. SH. 2017. We open Central Asia: prospects for the development of tourism along the Great Silk Road paths. Service in Russia and abroad, vol. 11, issue 6, (76).

YESAYDAR U.S. - BELGIBAYAV A.K. - MERSAKYLOVA G.R. 2016. The role of developing direction of international tourism in Kazakhstan, THE BULLETIN OF THE NATIONAL ACADEMY OF SCIENCES OF THE REPUBLIC OF KAZAKHSTAN, issue 2, $180 \mathrm{p}$.

Words: 6098

Characters: 39695 (22,05 standard pages)

assoc. professor Baltabayeva Alyona Yuldashkyzy

Director of the Department of Science and Innovations of the International KazakhTurkish

University named after Khoja Ahmed Yassawi

Turkistan

alyona.baltabayeva@ayu.edu.kz

Rizakhojayeva Gulnara Abdumajitkyzy, PhD.

Philology faculty, English Philology Department

Khoja Ahmed Yassawi Kazakh-Turkish University

Turkistan

gulnara_rizahodja@mail.ru

XLinguae, Volume 12, Issue 3, June 2019, ISSN 1337-8384, eISSN 2453-711X 